\title{
FIELD INVESTIGATION OF SIZE DISTRIBUTION OF SUSPENDED SEDIMENT USING LISST-100
}

\author{
Yoshiaki Kuriyama ${ }^{1}$, Takayuki Suzuki², Shin-ichi Yanagishima ${ }^{3}$, Ken-ichi Uzaki ${ }^{4}$, Yoshio \\ Ishino $^{5}$ and Hikari Sakamoto ${ }^{6}$
}

\begin{abstract}
To investigate size distributions of suspended sediments in the surf zone, a field measurement using LISST (Laser InSitu Scatter and Transmissometer) was conducted at Hasaki, Japan. The time series of suspended sediment concentration (SSC) for a grain size in the sand range (63 to $500 \mu \mathrm{m}$ ) had strong correlations with those for other sand grain sizes, and the strong correlations were also observed in the silt range ( 2.5 to $28 \mu \mathrm{m})$. However, at zero time lag, the time series of SSC for sand grain sizes had little correlations with those for silt sizes. With considering time lag, the time series of SSC for sand sizes had weak correlations with those for silt sizes, but which time series lagged behind the others, sand particles or silt particles, was not clear. When the total SSC $C_{\text {LISST }}$ was larger than $0.2 \mathrm{~g} / 1$, the median sediment diameter $d_{50}$ was scattered around $185 \mu \mathrm{m}$. However, at $C_{\mathrm{LISST}}<0.2 \mathrm{~g} / \mathrm{l}, d_{50}$ increased as $C_{\mathrm{LISST}}$ increased. With the increase in $d_{50}$ from 150 to $200 \mu \mathrm{m}$, the sorting coefficient decreased from 2.4 to 1.2 and the skewness increased from 0.7 to 1.0 .
\end{abstract}

Keywords: suspended sediment; grain size; surf zone; field measurement

\section{INTRODUCTION}

The sediment size is one of the key factors affecting nearshore environments including coastal processes. Sediments in the field have various sizes even if they are well sorted. However, in spite of the recent investigations through laboratory experiments (e.g., Tanaka et al. 2000) and field measurements (e.g., Okayasu and Katayama 2000, Kato et al. 2007), size distributions of suspended sediments in the surf zone are not fully understood. Hence, using Laser In-Situ Scatter and Transmissometer (LISST), which is able to measure suspended sediment concentrations at various grain sizes, a field measurement of suspended sediment was conducted to investigate size distributions of suspended sediments in the surf zone.

\section{FIELD MEASUREMENT AND ANALYSIS}

A LISST-100X (type C) uses laser diffraction to measure the suspended sediment concentrations (SSC) of 32 grain size bins ranging from 2.5 to $500 \mu \mathrm{m}$ (Sequoia Scientific Inc.). Although the validity of the measurement using LISST has been widely investigated (e.g., Creed et al. 2001, Gartner et al. 2001, Fugate and Friedrichs 2002, Mikkelsen et al. 2005), for example, by comparing the suspended sediment concentrations measured using LISST with those measured using OBS and ADV, the validations were conducted mostly under silt-dominant conditions and rarely under sand-dominant conditions.

The field measurement of suspended sediment was carried out at the Hazaki Oceanographical Research Station (HORS, Photo 1) located on the Hasaki coast in Japan during a period from January 30 to February 17, 2008, for 20 minutes every 2 hours. HORS has a $427-\mathrm{m}$-long pier, and along the pier, the beach profile was measured every weekday at 5-m intervals. A LISST-100X and an optical backscatter sensor (OBS) were installed approximately $30 \mathrm{~cm}$ above the bottom of the initial profile at a measurement point in the surf zone (Fig. 1). The OBS was calibrated with sediments sampled at the foreshore, of which the median size was $220 \mu \mathrm{m}$ on the basis of a sieve analysis. The sampling frequencies were $0.5 \mathrm{~Hz}$ for LISST and $2 \mathrm{~Hz}$ for OBS. An optical bed level sensor was also installed at the measurement point; it detects the bed level at 30 minutes intervals by measuring the light transmission rate at $2.5 \mathrm{~cm}$ vertical intervals. Figure 2 shows the time series of the elevation at the measurement point measured by the bed level sensor and the daily survey. The water depth during the measurement ranged from 1 to $3 \mathrm{~m}$.

\footnotetext{
${ }_{1}^{1}$ Port and Airport Research Institute, Nagase 3-1-1, Yokosuka, Kanagawa 239-0826, Japan, kuriyama@pari.go.jp

2 Institute of Urban Innovation, Yokohama National University, Tokiwadai 79-5, Hodogaya-ku, Yokohama, Kanagawa 240-8501, Japan

3 Port and Airport Research Institute, Nagase 3-1-1, Yokosuka, Kanagawa 239-0826, Japan

${ }^{4}$ Graduate School of Engineering, Gunma University, Tenjin-cho 1-5-1, Kiryu, Gunma 376-8515, Japan

${ }^{5}$ Fushiki-Toyama Port Office, Hokuriku Regional Development Bureau, Ministry of Land, Infrastructure, Transport and Tourism, Ushijima-shinmachi 11-3, Toyama-shi, Toyama 930-0856, Japan

${ }^{6}$ Praia Co. Ltd., Hisamoto 3-3-15, Aioi-Sonpo Bldg., Takatsu-ku, Kawasaki, Kanagawa 231-0011, Japan
} 


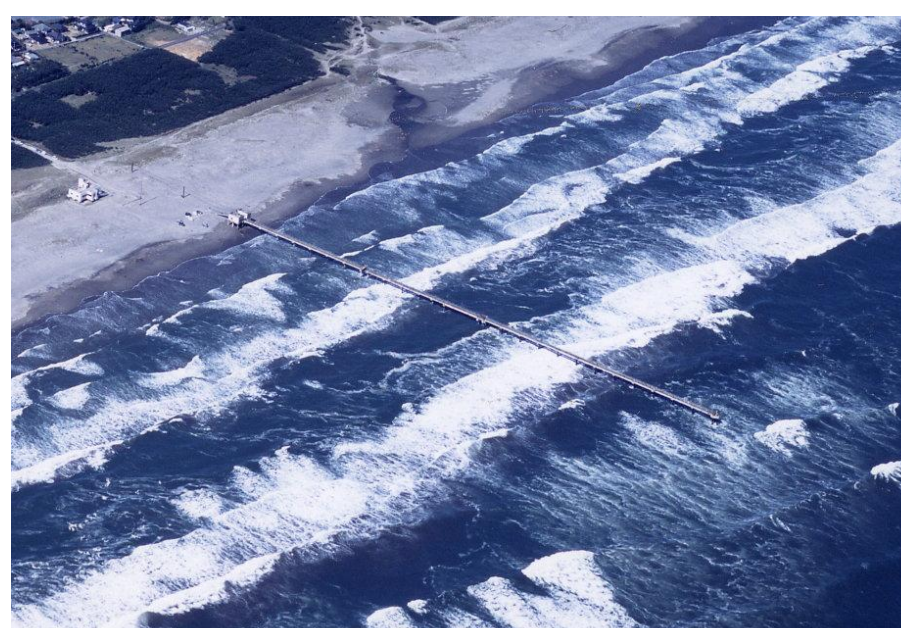

Photo 1. Aerial photo of HORS.

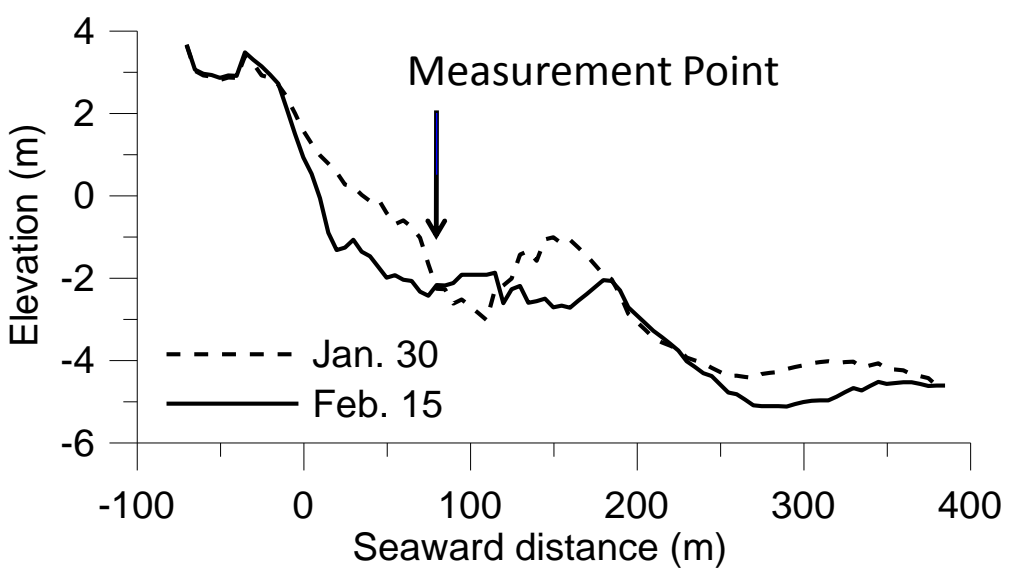

Figure 1. Location of the measurement point and the beach profile change during the measurement. The elevation is based on the datum level at Hasaki.

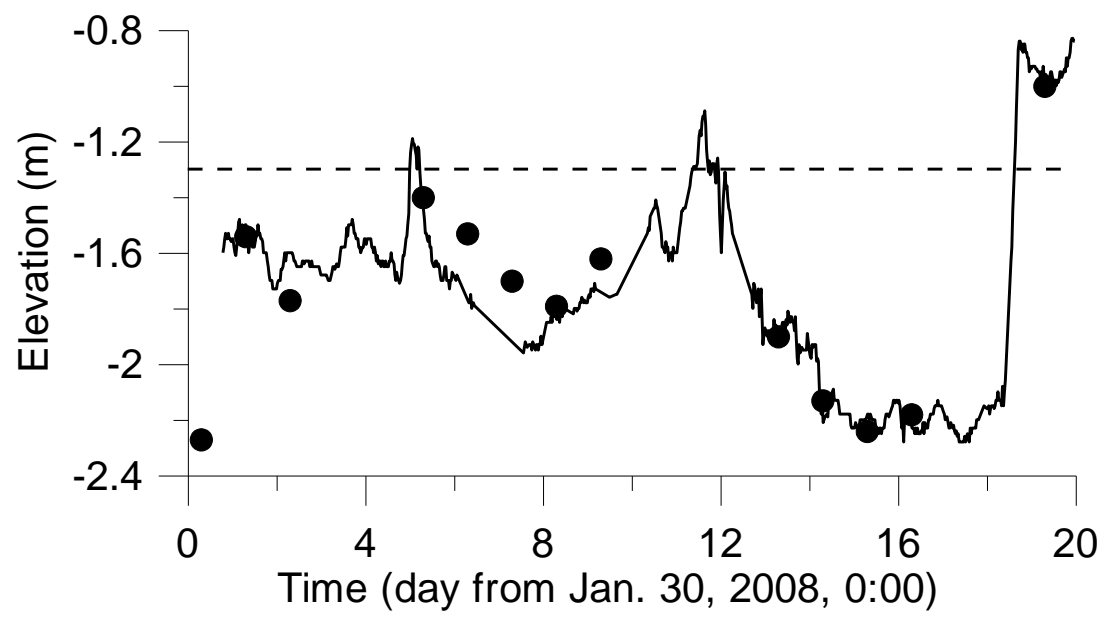

Figure 2. Time series of the elevation at the measurement point. The solid line and solid circles show the values measured by the bed level sensor and the daily survey, respectively. The dotted line shows the vertical location of LISST and OBS. 


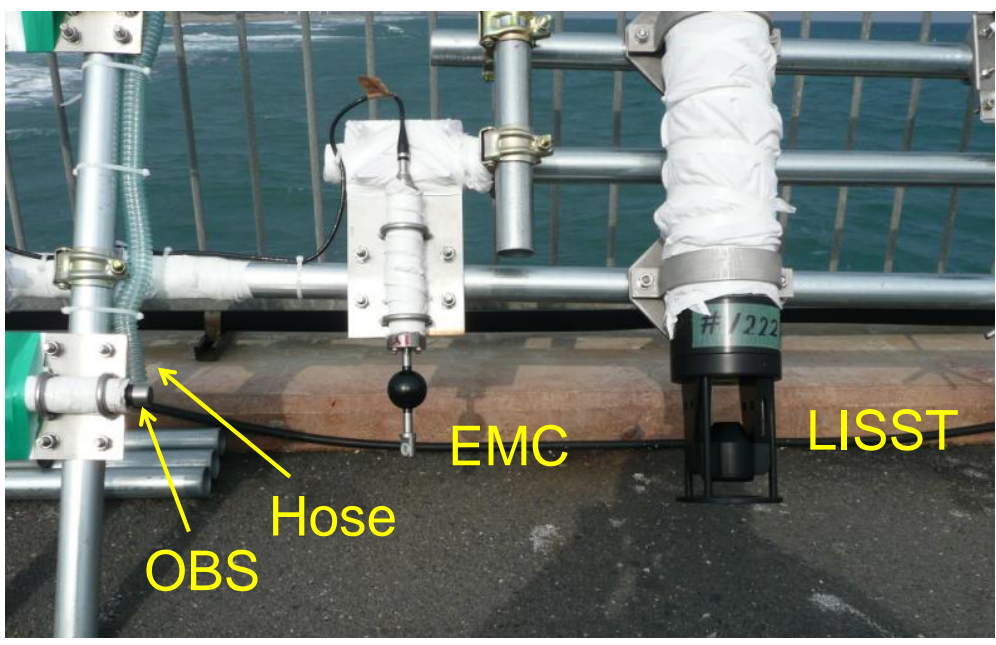

Photo 2. Instruments installed at the measurement point. EMC denotes Electromagnetic Current meter; the data obtained by the EMC were not used in this study.

In addition to the measurements mentioned above, sea water containing suspended sediments was sampled three times on February 8 by pumping water through a hose set next to the OBS (Photo 2). The duration times and the volumes of the water sampling were $21.8 \mathrm{~s}, 14.5 \mathrm{~s}$ and $38.3 \mathrm{~s}$, and $14.6 \times$ $10^{-3} \mathrm{~m}^{3}, 9.6 \times 10^{-3} \mathrm{~m}^{3}$ and $20.0 \times 10^{-3} \mathrm{~m}^{3}$, respectively.

As for the LISST data, the time-averaged SSC of the 32 grain sizes for 20 minutes $C(d)$, where $d$ is the grain size in units of $\mu \mathrm{m}$, and their summation $C_{\text {LISST }}$ were estimated. Then, based on $C(d)$, the median sediment diameter $d_{50}$, the sorting coefficient $s_{0}\left(=\sqrt{d_{75} / d_{25}} ; d_{25}\right.$ and $d_{75}$ are the 25th and 75th percentile grain sizes, respectively.) and the skewness $s_{\mathrm{k}}\left(=\left(d_{75} d_{25}\right) / d_{50}^{2}\right)$ were obtained.

Figure 3 shows the time series of offshore wave height, $s_{0}, s_{\mathrm{k}}, d_{50}, C(24), C(201), C_{\mathrm{LISST}}$ and $C_{\mathrm{OBS}}$, which is the time-averaged SSC measured with the OBS. The offshore wave height was measured for 20 minutes every 2 hours at a water depth of $30 \mathrm{~m}$ off the Hitachinaka Port, which is located $50 \mathrm{~km}$ north of the measurement site.

The value of $C(201)$ increased and decreased according to the increase and decrease in the offshore wave height, respectively. However, $C(24)$ did not correlate to the wave height variation. The values of $s_{0}, s_{\mathrm{k}}$ and $d_{50}$ seem to have strong correlations with each other.

\section{RESULTS AND DISCUSSION}

\section{Median Sediment Diameters Obtained by Three Methods}

The values of $d_{50}$ of the sediments included in the sampled waters were examined using the LISST and sieves. The values of $d_{50}$ obtained by the sieve analysis were slightly smaller than those using LISST (Fig. 4). However, the root-mean-square error was $15 \mu \mathrm{m}$ and the difference was small.

Then, $d_{50}$ of the sampled sediments examined using the LISST were compared with those directly measured in the sea using the LISST. Although an error was $18 \mu \mathrm{m}$, the other two errors were $4 \mu \mathrm{m}$, and the root-mean-square error was $11 \mu \mathrm{m}$. Hence, the difference was also negligible.

\section{SSC Obtained by Three Methods}

The comparison between the SSC obtained through the water sampling and measured using the LISST shows that the root-mean-square error was $0.12 \mathrm{~g} / \mathrm{l}$ and the difference was small (Fig. 5). However, the SSC measured using the OBS were several times larger than those obtained through the water sampling and measured using the LISST.

The total SSC measured using the LISST $C_{\text {LISST }}$ were compared with those measured using the OBS $C_{\mathrm{OBS}}$ (Fig. 6). The values of $C_{\mathrm{OBS}}$ were larger than $C_{\mathrm{LISST}}$. The reason is probably the difference in size of the sediments suspended in the field and used in the OBS calibration. An OBS measures the suspended sediment concentration by detecting infrared radiation scattered from a suspended sediment (D \& A Instrument Co. 1991), which is proportional to the section area of the sediment. Hence, even when the suspended sediment concentration is the same, the intensity of infrared radiation, which is proportional to the output voltage, is larger for finer sediments than for coarser sediments. Although the 


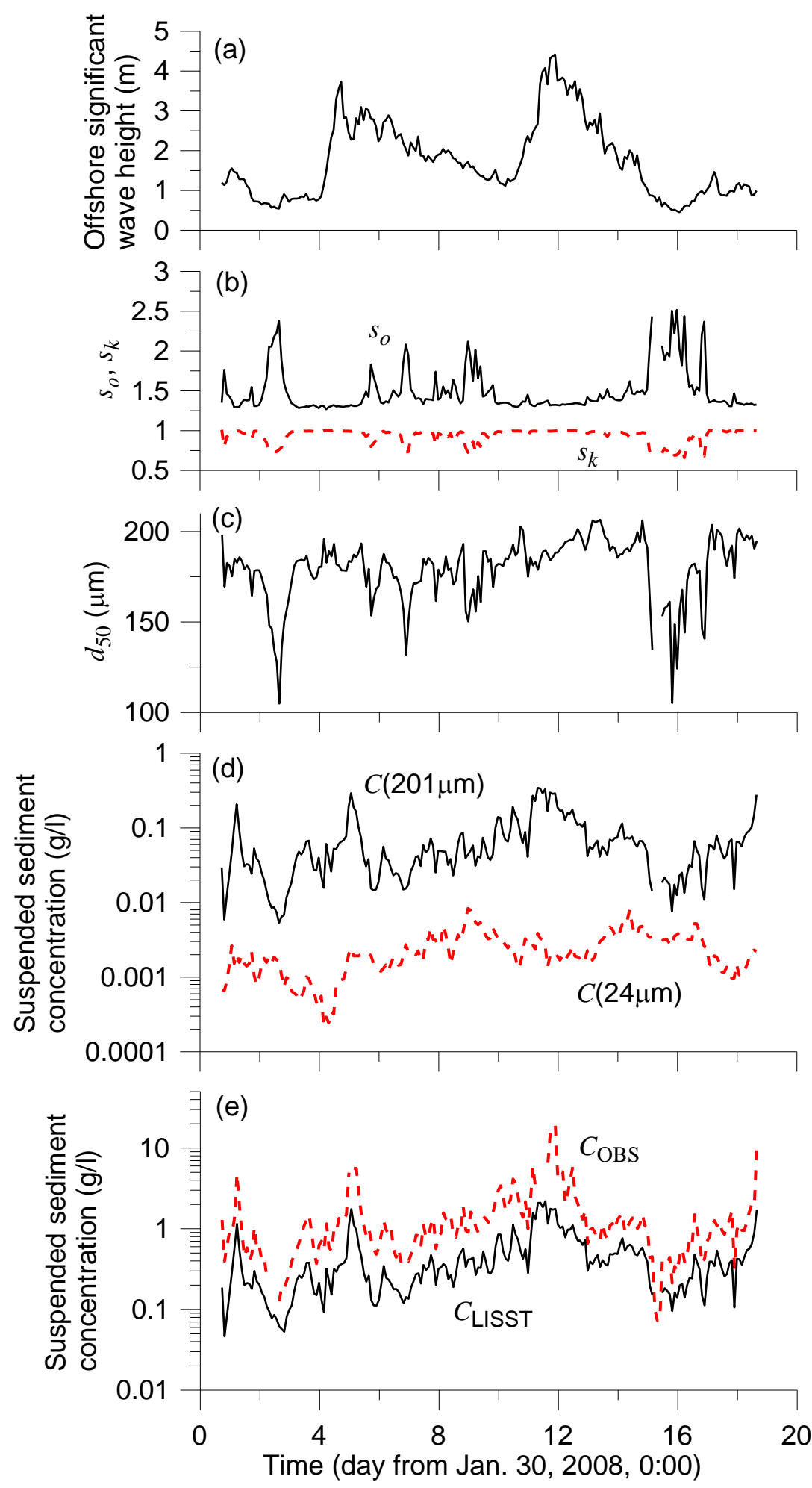

Figure 3. Time series of (a) offshore wave height, (b) $s_{\mathrm{o}}$ and $s_{\mathrm{k}}$, (c) $d_{50}$, (d) $C(24)$ and $C(201)$, and (e) $C_{\mathrm{LISST}}$ and Coвs. 


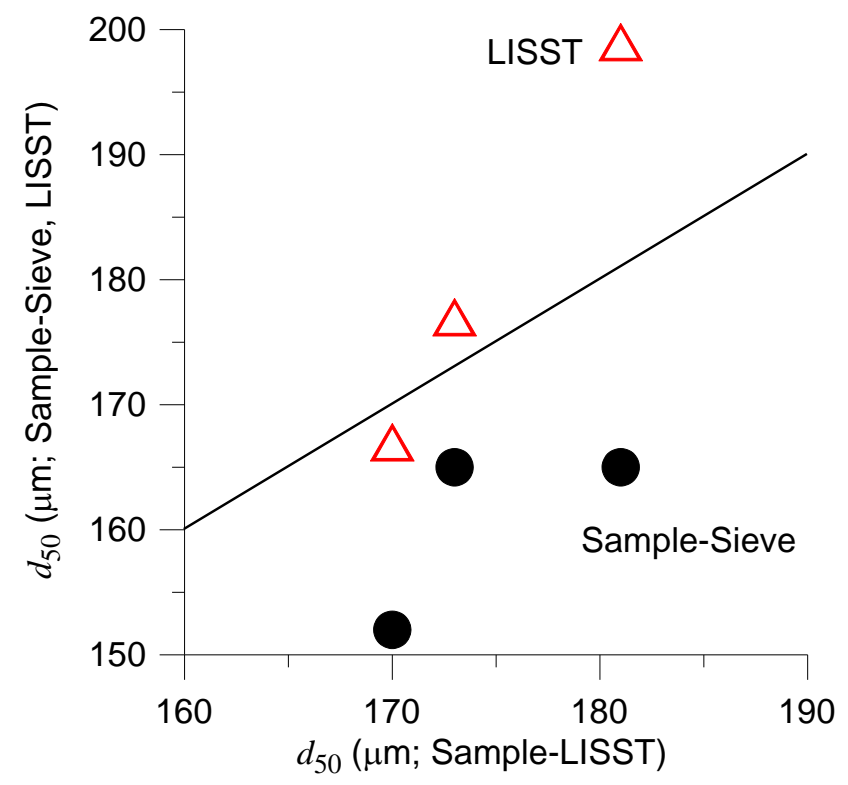

Figure 4. Comparison between $d_{50}$ of the sediments in the sampled waters examined using the LISST and sieves (black solid circles), and that between $d_{50}$ of the sediments in the sampled waters examined using the LISST and $d_{50}$ directly measured in the sea using the LISST (red open triangles).

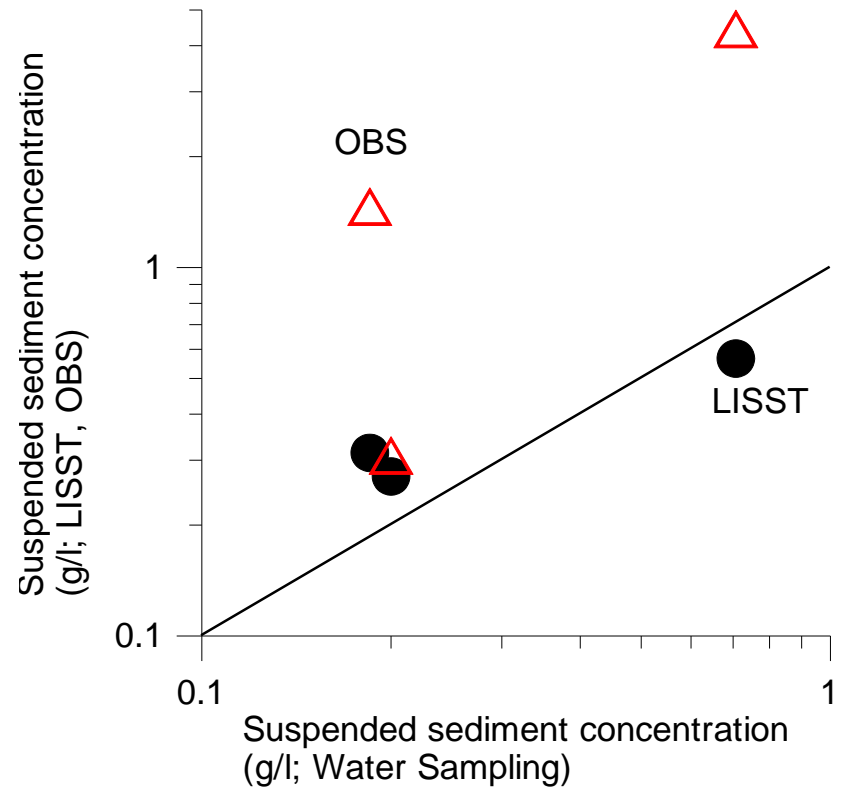

Figure 5. Comparison between SSC obtained through the water sampling and measured using the LISST (black solid circles) and the OBS (red open triangles).

size of the sediments used in the calibration was $220 \mu \mathrm{m}$, that of the suspended sediment was mostly smaller than $200 \mu \mathrm{m}$ (Fig. 3). As a result, $C_{\mathrm{OBS}}$ became larger than $C_{\mathrm{LISST}}$.

Although $C_{\mathrm{OBS}}$ were larger than $C_{\mathrm{LISST}}, C_{\mathrm{LISST}}$ and $C_{\mathrm{OBS}}$ had a strong linear correlation when $C_{\mathrm{LISST}}$ was small (Fig. 6). The linearity of the correlation between $C_{\mathrm{LISST}}$ and $C_{\mathrm{OBS}}$ was investigated by fitting a linear function and a quadratic function to the correlation between them, estimating the AIC values for those two functions (Akaike 1973, Sakamoto et al. 1986) and determining the better function on the basis of the AIC values. When the linear function was better than the quadratic function, their correlation was assumed to be linear. The investigations were repeatedly conducted by increasing the upper limit of $C_{\mathrm{OBS}}$ used in the investigation from 0.4 to $8.0 \mathrm{~g} / \mathrm{l}$. The result is that the correlation was linear at $C_{\mathrm{LISST}}<1 \mathrm{~g} / \mathrm{l}$. 
The suspended sediment concentration measured using an OBS is sensitive to the sediment size as mentioned above. However, once an OBS is properly calibrated, it is able to measure relatively high concentrations, up to $20 \mathrm{~g} / \mathrm{l}$ according to the calibration result shown by Kuriyama et al. (2005). Although $C_{\mathrm{OBS}}$ were larger than the real values in this study, $C_{\mathrm{OBS}}$ are expected to be proportional to the real values. If so, the upper limit of the linear correlation between $C_{\mathrm{LISST}}$ and $C_{\mathrm{OBS}}, 1 \mathrm{~g} / \mathrm{l}$, indicates the upper limit of the measurement range of the LISST. The value of $1 \mathrm{~g} / \mathrm{l}$ was close to the value listed in the brochure of LISST-100X, $0.75 \mathrm{~g} / \mathrm{l}$ (Sequoia Scientific Inc.).

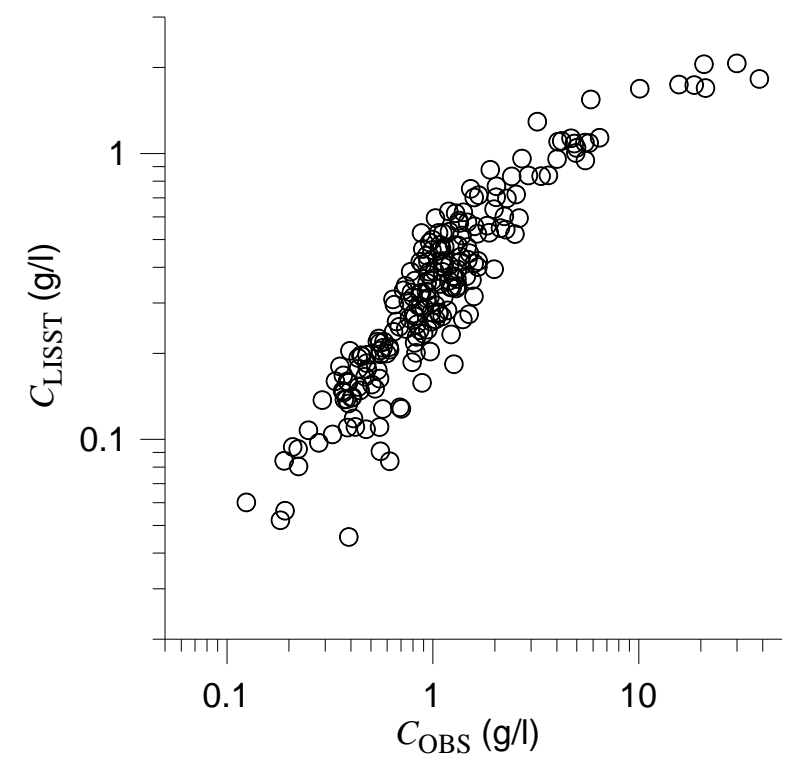

Figure 6. Comparison between $C_{\mathrm{OBS}}$ and $C_{\text {LISST }}$.

\section{Correlations among the Time Series of SSC for Various Sizes}

The correlation coefficients between the time series of SSC for grain sizes from 2.5 to $500 \mu \mathrm{m}$ were investigated with and without considering time lag. At zero lag, the time series of SSC for a grain size in the sand range (63 to $500 \mu \mathrm{m})$ had strong correlations with those for other sand grain sizes (Fig. 7). The same strong correlations were also observed in the silt range $(2.5$ to $28 \mu \mathrm{m})$. However, the time series of SSC for sand particles had little correlations with those of silt particles as suggested by Fig. 3.

The result shown above is similar to that obtained by Kato et al. (2007), which showed that the time series of SSC for relatively coarse sediments had negative correlations with those for relatively fine sediments. However, the boundary between the strong and little or negative correlations was $200 \mu \mathrm{m}$ in the study of Kato et al. (2007), which was larger than that in this study, 30 to $60 \mu \mathrm{m}$.

In lag correlation analysis, the maximum lagged correlation coefficient between the time series of SSC of two grain sizes was defined as the maximum among the correlation coefficient values obtained with time lags ranging from -3.3 to 3.3 days, and the optimal time lag was defined as the time lag with the maximum lagged correlation coefficient. While at zero lag, most of the correlations between the time series of SSC for sand and silt particles had coefficients smaller than 0.2 (Fig. 7), their maximum lagged correlation coefficients were mostly larger than 0.4, which means that the time series of SSC of sand particles had weak correlations with those of silt particles. However, which time series lagged behind the others, sand particles or silt particles, was unclear because the optimal time lags had positive and negative values, which largely ranged from 2.3 to 2.5 days and from -2.8 to -2.6 days, respectively (Fig. 9). The positive and negative optimal time lags resulted from the fact that the lagged correlation coefficient between the time series of SSC of a sand grain size and a silt size, which was obtained by changing the time lag from -3.3 to 3.3 days as mentioned above, had two peaks at around 2.3 days and -2.6 days as shown in Fig. 10. The two peaks were formed because the time series of SSC of sand and silt particles had high coherence at around the 5-day period, and were in opposite phase to each other at that period. However, the causes of the high coherence and the opposite phase were not found. 


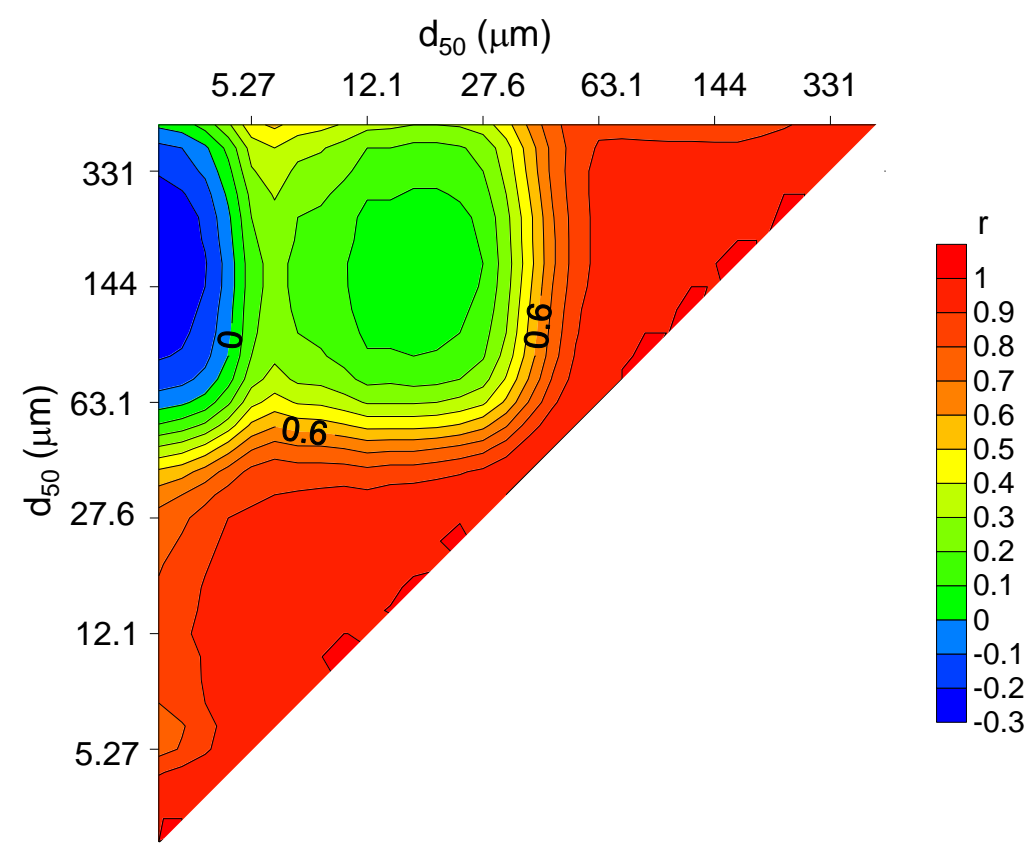

Figure 7. Correlation coefficients between the time series of SSC for grain sizes from 2.5 to $500 \mu \mathrm{m}$ at zero lag. Warm colors represent strong correlations.

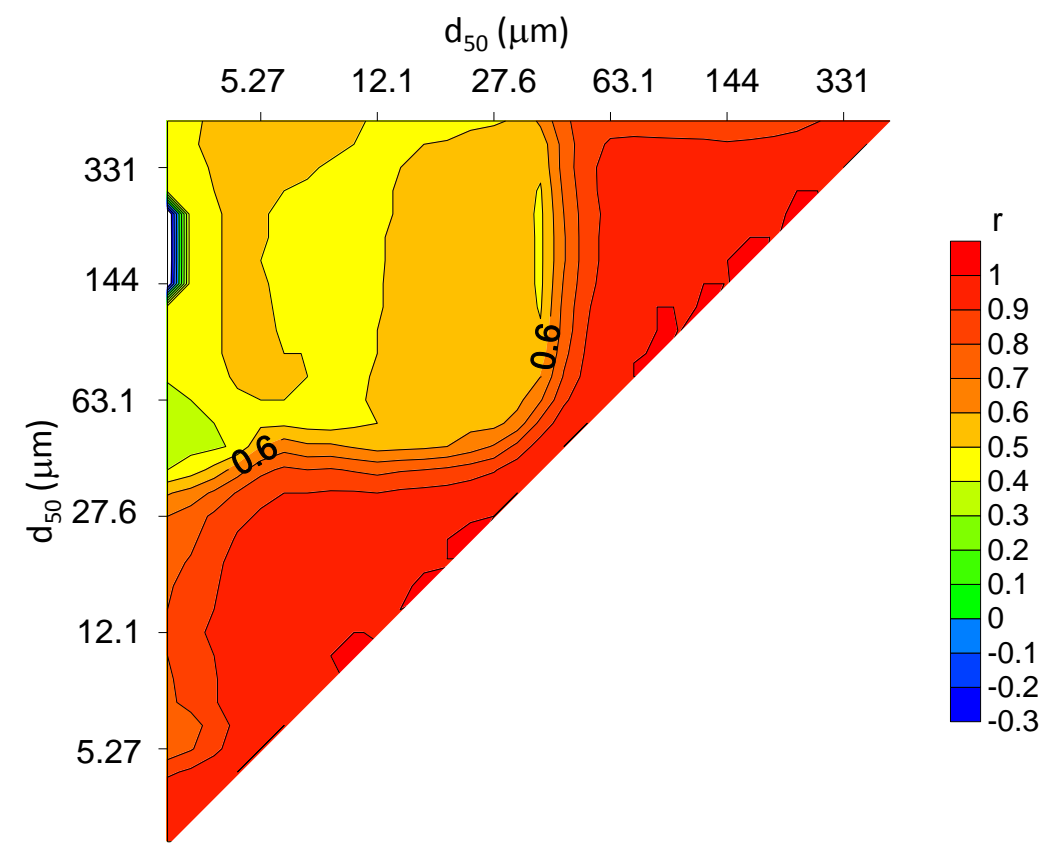

Figure 8. Maximum lagged correlation coefficients between the time series of SSC for grain sizes from 2.5 to $500 \mu \mathrm{m}$. 


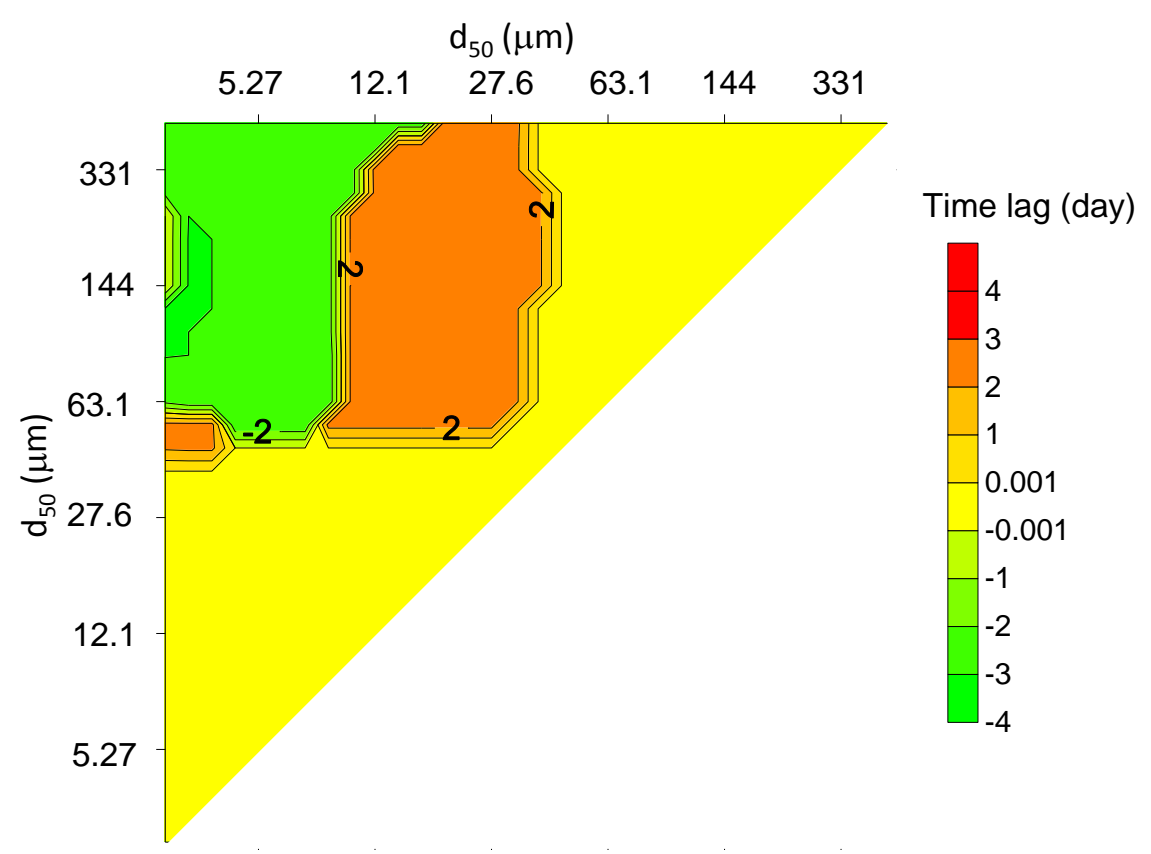

Figure 9. Optimum time lags between the time series of SSC for grain sizes from 2.5 to $500 \mu \mathrm{m}$. A positive value indicates that the time series of SSC of a grain size at the horizontal axis lags behind that at the vertical axis.

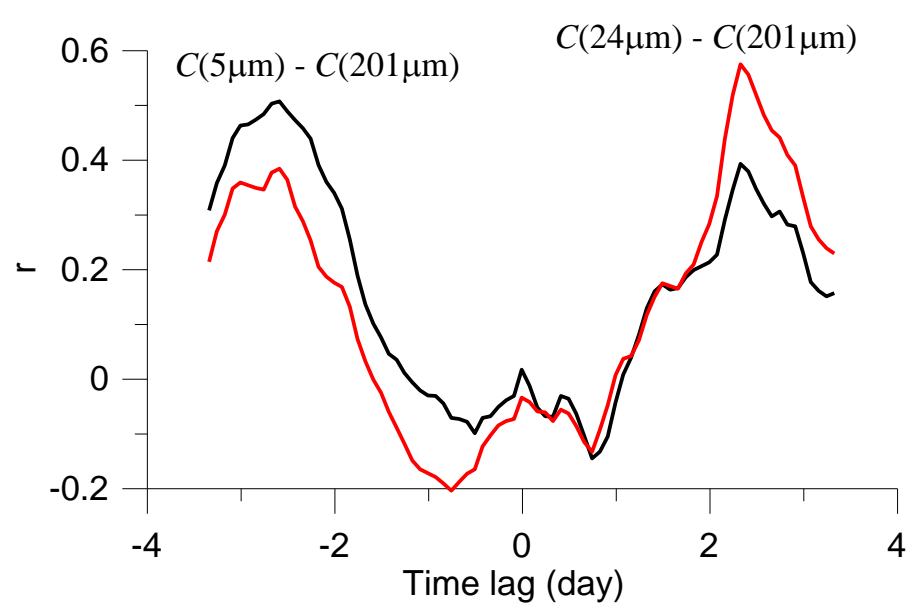

Figure 10. Lagged correlation coefficients between the time series of SSC for grain sizes of 5 and $201 \mu \mathrm{m}$ (black line) and 24 and $201 \mu \mathrm{m}$ (red line). A positive value of time lag indicates that the time series of SSC for the former grain size lags behind that for the latter one.

\section{Median Sediment Diameter and the Total SSC}

When the total SSC $C_{\text {LISST }}$ was larger than $0.2 \mathrm{~g} / \mathrm{l}$, the median sediment diameter $d_{50}$ was scattered around $185 \mu \mathrm{m}$ (Fig. 11). However, at $C_{\mathrm{LISST}}<0.2 \mathrm{~g} / \mathrm{l}, d_{50}$ increased as $C_{\mathrm{LISST}}$ increased. The size distributions of suspended sediments with different $d_{50}$ show that the peak diameters were located at 201 or $237 \mu \mathrm{m}$ and independent of $d_{50}$ (Fig. 12). This result indicates that the change in $d_{50}$ at $C_{\text {LISST }}<$ $0.2 \mathrm{~g} / \mathrm{l}$ (Fig. 11) was induced not by the shift of the peak diameter but by the change in the ratio of the weight of sand particles to that of silt particles.

It is possible that the distance from the bottom to the LISST has influences on $d_{50}$ and $C_{\mathrm{LISST}}$, but no correlations were observed between $d_{50}$ or $C_{\text {LISST }}$ and the distance from the bottom. 


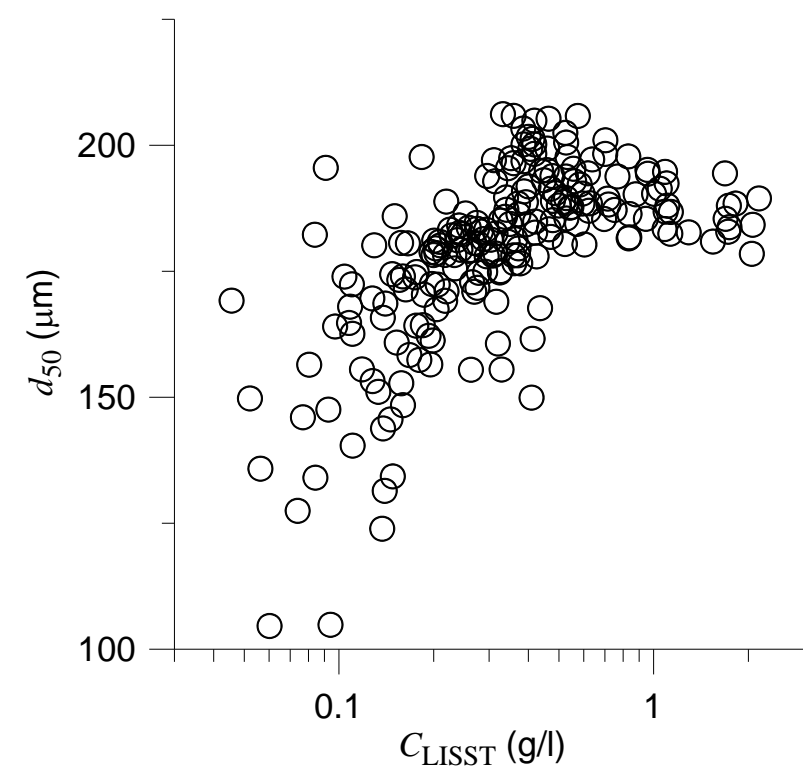

Figure 11. Relationship between $C_{\text {LISST }}$ and $d_{50}$.

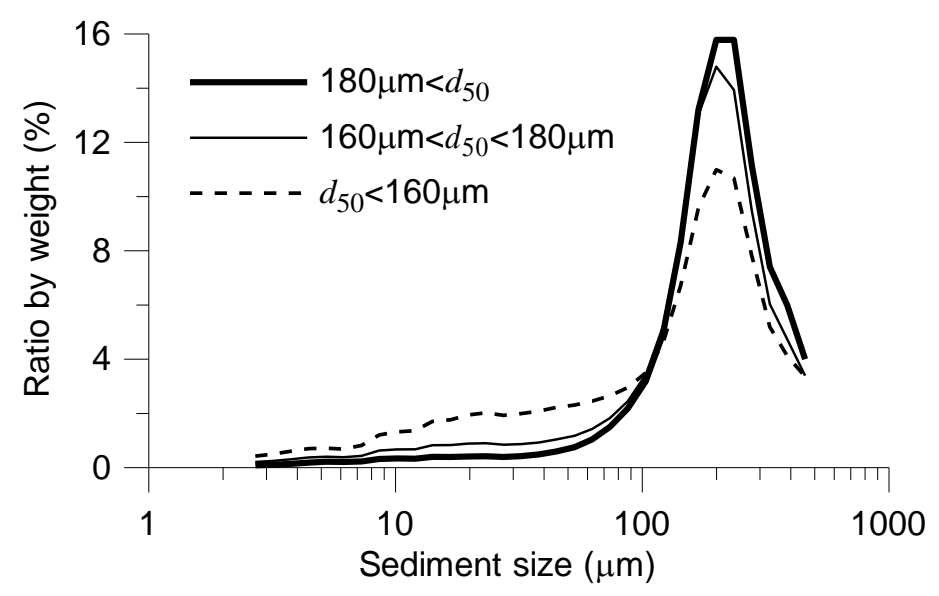

Figure 12. Averaged size distributions of suspended sediments with different $d_{50}$.

\section{Prediction of SSC of Various Sizes}

In the prediction of SSC, SSC is sometimes assumed to be inversely proportional to the sediment fall velocity. The assumption was examined through the two steps mentioned below. First, the SSC of various grain sizes were estimated by multiplying the weights of the grain sizes of the bottom sediments by the corresponding fall velocities. Then, the estimated SSC were compared with the measured ones. During the measurement period, bottom sediments were not collected at the measurement point, while those were collected every month during a period from June to October in 2005. In this study, sediments collected on June $10\left(d_{50}=179 \mu \mathrm{m}\right)$ and on September $29\left(d_{50}=403 \mu \mathrm{m}\right)$ were used.

When $d_{50}$ of the bottom sediment was small, the estimated size distribution of suspended sediment shifted toward finer sediments than the average size distribution of suspended sediment measured in the field (Fig. 13). However, when $d_{50}$ of the bottom sediment was large, the estimated size distribution fitted well with the measured average one, which may support the validity of the assumption for predicting SSC mentioned above. Of course, the result is not conclusive because the bottom sediments were not collected during the measurement. However, during the period from June to September in 2005, the coarse sediments continued to exist for two months, and hence the possibility that SSC is inversely proportional to the sediment fall velocity may not be low. 


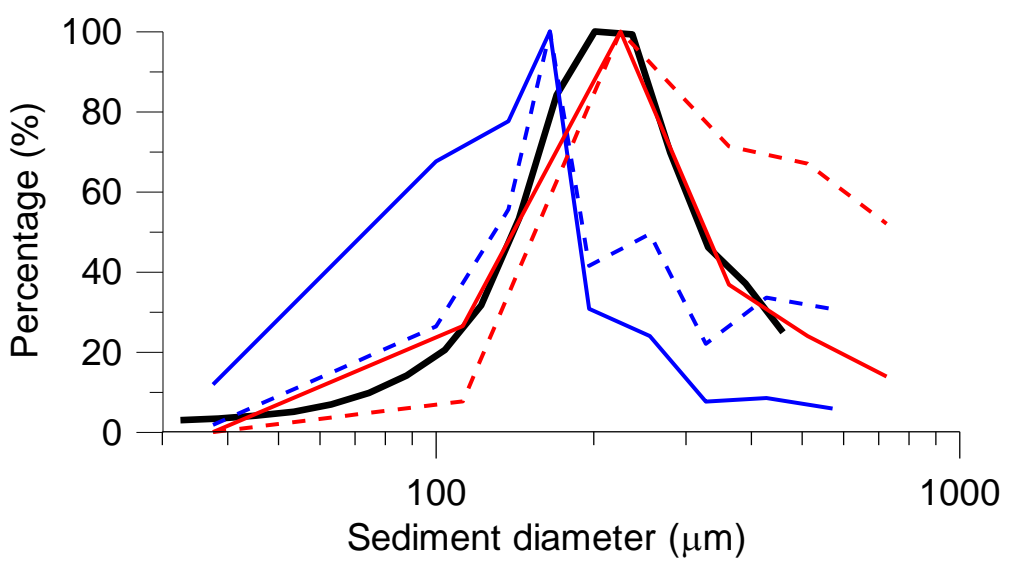

Figure 13. Size distributions of bottom sediment (June: blue broken line; September: red broken line), the estimated ones of suspended sediment (June: blue solid line; September: red solid line) and the measured average one of suspended sediment (black line).

\section{Sorting Coefficient and Skewness}

With the increase in $d_{50}$, the sorting coefficient $s_{0}$ decreased from 2.4 to 1.2 and the skewness $s_{\mathrm{k}}$ increased from 0.7 to 1.0 (Fig. 14). As expected from the definitions, $s_{\mathrm{o}}$ gets smaller as the grain size distribution gets more sharpened and sediments are more sorted. The value of $s_{\mathrm{k}}$ approaches toward 1.0 as the size distribution gets more symmetric. As shown in Fig. 12, with the increase in $d_{50}$, the ratio of the weight of silt particles to that of sand particles decreased, which indicates that the sediments were more sorted and that the size distribution got more symmetric. As a result, as $d_{50}$ increased, $s_{\mathrm{o}}$ and $s_{\mathrm{k}}$ changed from 2.4 to 1.2 and from 0.7 to 1.0 , respectively.

Although our results showed that as $d_{50}$ decreased from $200 \mu \mathrm{m}, s_{\mathrm{o}}$ increased and $s_{\mathrm{k}}$ decreased (Fig. 14), Katoh and Yanagishima (1997) showed that for bottom sediments collected at Hasaki, as $d_{50}$ decreased from $200 \mu \mathrm{m}$, both $s_{\mathrm{o}}$ and $s_{\mathrm{k}}$ decreased and approached toward 1.0. A potential cause of the difference of the results is the difference in the testing method. The minimum size of the sieves reported by Katoh and Yanagishima (1997) was $53 \mu \mathrm{m}$. On the other hand, the LISST measures SSC for 18 grain sizes smaller than $53 \mu \mathrm{m}$, and $d_{25}$ was sometimes smaller than $53 \mu \mathrm{m}$ in this study. However, when we recalculated $s_{\mathrm{o}}$ and $s_{\mathrm{k}}$ by replacing $d_{25}$ smaller than $53 \mu \mathrm{m}$ with $53 \mu \mathrm{m}$, the results were not much different from those shown in Fig. 14. Hence, the difference in the testing method is not a cause of the difference between our results and those of Katoh and Yanagishima. Further investigation is required.
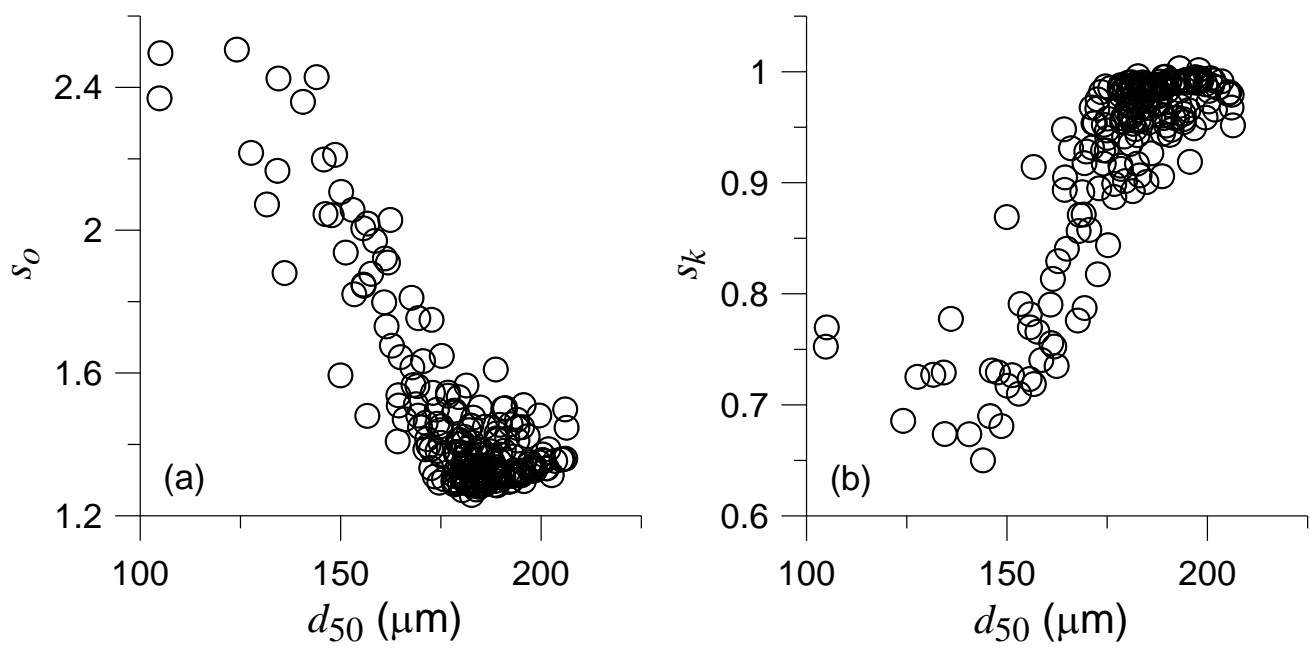

Figure 14. Relationships (a) between $d_{50}$ and $s_{\circ}$ and (b) between $d_{50}$ and $s_{k}$. 


\section{COCLUSIONS}

A field measurement of suspended sediment was conducted at the Hazaki Oceanographical Research Station located in eastern Japan during a period from January 30 to February 17 in 2008 for 20 minutes every 2 hours to investigate size distributions of suspended sediments in the surf zone. A Laser In-Situ Scatter and Transmissometer (LISST), which is able to measure suspended sediment concentrations at various grain sizes, and an optical backscatter sensor were installed approximately 30 $\mathrm{cm}$ above the bottom of the initial profile at a measurement point, where the water depth ranged from 1 to $3 \mathrm{~m}$ during the measurement.

The time series of suspended sediment concentration (SSC) for a grain size in the sand range (63 to $500 \mu \mathrm{m}$ ) had strong correlations with those for other sand grain sizes. The strong correlations were also observed in the silt range $(2.5$ to $28 \mu \mathrm{m})$. However, at zero lag, the time series of SSC for sand particles had little correlations with those for silt particles. The lag correlation analysis showed that the correlations between the time series of SSC for sand and silt particles were weak, but there was no clear indication of which time series lagged behind the others, sand particles or silt particles.

When the total SSC $C_{\text {LISST }}$ was larger than $0.2 \mathrm{~g} / \mathrm{l}$, the median sediment diameter $d_{50}$ was scattered around $185 \mu \mathrm{m}$. However, at $C_{\mathrm{LISST}}<0.2 \mathrm{~g} / \mathrm{l}, d_{50}$ increased as $C_{\mathrm{LISST}}$ increased. Because the peak diameters were located at 201 or $237 \mu \mathrm{m}$ and independent of $d_{50}$, the change in $d_{50}$ at $C_{\mathrm{LISST}}<0.2 \mathrm{~g} / \mathrm{l}$ was assumed to be induced not by the shift of the peak diameter but by the change in the ratio of the weight of sand particles to that of silt particles.

With the increase in $d_{50}$ from 130 to $200 \mu \mathrm{m}$, the sorting coefficient decreased from 2.4 to 1.2 and the skewness increased from 0.7 to 1.0 . This is because as $d_{50}$ increased, the sediments were more sorted and the size distribution got more symmetric.

\section{REFERENCES}

Akaike, H. 1973. Information theory and an extension of the maximum likelihood principle, 2nd International Symposium on Information Theory, 267-281.

Creed, E.L., A.M. Pence, and K.L. Rankin. 2001. Inter-comparison of turbidity and sediment concentration measurements from an ADP, an OBS-3, and a LISST, OCEANS 2001: MTS/IEEE Conference and Exhibition 3, 1750-1754.

D \& A Instrument Co. 1991. OBS-1 \& 3 Suspended Solids \& Turbidity Monitor Instruction Manual, $41 \mathrm{pp}$.

Fugate, D.C., and C.T. Friedrichs. 2002. Determining concentration and fall velocity of estuarine particle populations using ADV, OBS and LISST, Continental Shelf Research, 22, 1867-1886.

Gartner, J.W., R.T. Cheng, P.F. Wang, and K. Richter. 2001. Laboratory and field evaluations of the LISST-100 instrument for suspended particle size determinations, Marine Geology, 175, 199-219.

Kato. S., S. Aoki, and H. Torii. 2007. Temporal variation of graded suspended sediment concentration in the surf zone, Journal of Coastal research, SI 50 (Proceedings of ICS 2007), 302-306.

Katoh, K., and S. Yanagishima. 1995. Changes of sand grain distribution in the surf zone, Proceedings Coastal Dynamics '95, ASCE, 639-650.

Kuriyama, Y., S.-H. Shin, and S. Ueoka. 2005. Field measurements on sediment transport near the shoreline under developed long period waves during a storm, Proceedings of Coastal Dynamics '05, ASCE, CD-ROM.

Mikkelsen, O.A., P.S. Hill, T.G. Milligan, and R.J. Chant. 2005. In situ particle size distributions and volume concentrations from a LISST-100 leaser particle sizer and a digital floc camera, Continental Shelf Research, 25, 1959-1978.

Okayasu, A., and H. Katayama. 2000. Field Experiments on temporal change of suspended sediment concentration and grain size distribution in surf zone, Proceedings of 27th international Conference on Coastal Engineering, ASCE, 3359-3372.

Sakamoto, Y., M. Ishiguro, and G. Kitagawa. 1986. Akaike Information Criterion Statics, KTK Scientific Publishers, 288pp.

Sequoia Scientific Inc. http://www.sequoiasci.com/products/fam_LISST_100.aspx

Tanaka, M., R. Inoue, S. Sato, M. Isobe, A. Watanabe, M. Ikeno, and T. Shimizu. 2000. Large wave tank experiments on profile change and cross-shore sand transport rate of mixed grain size beach, Proceedings on Coastal Engineering, JSCE, 47, 551-555. (in Japanese) 